\section{Meningitis crónica autoinmune secundaria a meningitis aguda por neumococo. Caso clínico}

\author{
GABRIEL CEA $^{1,2}$, SILVIA BARRIA ${ }^{1}$, \\ VICTORIA LEIDERMAN ${ }^{3}$, LUIS CARTIER ${ }^{1,2}$
}

\section{Autoimmune chronic meningitis secondary to pneumococcal meningitis. Report of one case}

Pneumococcal meningitis produces several inflammatory disorders in susceptible subjects. A worsening of meningitis can occur on the fourth day of evolution in relation with the withdrawal of steroids. Other complications include the development of inflammatory signs in the post-acute stage of infection associated with disseminated vasculitis of the cerebral blood vessels and, even later, an autoimmune chronic meningitis. All these inflammatory complications are well controlled with the use of steroids. We report a 53-year-old woman with pneumococcal meningitis that had a good response to treatment with antibiotics and steroids. On the four day, after the steroids were discontinued, she complained of headache, became confused, and had an abnormal cerebrospinal fluid (CSF), report CT angiography showed signs of arteritis. She improved when the steroids were re-started. She was discharged in good condition but after slow tapering of the steroids over a four-month period she had a relapse of all her symptoms and had a gait disturbance. On readmission, she had an inflammatory CSF, there were no signs of infection and the cerebral MRI showed meningeal thickening with ventricular space enlargement. She improved again with steroids and she is now well on high-dose steroids but deteriorates each time the steroids are stopped. She experienced both acute and sub-acute inflammatory responses and finally developed a chronic meningitis responsive, and is dependent on steroids.

(Rev Med Chile 2019; 147: 803-807)

Key words: Hydrocephalus; Meningitis; Meningitis, Pneumococcal; Streptococcus pneumoniae.

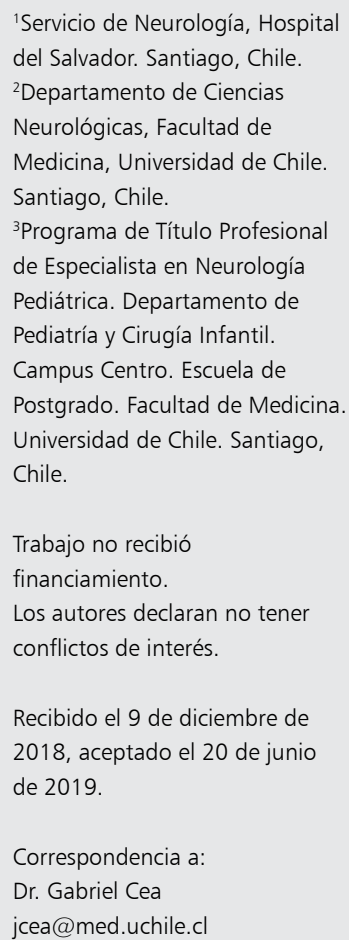

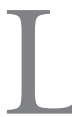

as meningitis bacterianas tienen una incidencia de 1,27 a 2,6 por 100.000 habitantes. El Streptococcus pneumoniae es la bacteria que con mayor frecuencia infecta el sistema nervioso central (SNC) causando $51 \%$ a $58 \%$ de todos los casos de meningitis ${ }^{1,2}$ por alguna de las más de cincuenta cepas conocidas de neumococo ${ }^{3}$. La meningitis bacteriana es una infección grave, cuya mortalidad fluctúa de $13 \%$ a $30 \%$ y el neumococo contribuye con $70 \%$ de los decesos ${ }^{1,2}$.

Clásicamente, el neumococo llega al SNC cruzando la barrera hematoencefálica de manera encubierta; las bacterias activarían proteínas estreptococales que interactuarían con receptores de los linfocitos CD46, logrando su endocitocis con la ayuda de factores plaquetarios ${ }^{3}$. El ingreso del neumococo al SNC genera una respuesta inflamatoria en las meninges y en la pared vascular de medianas arterias y venas. El $97 \%$ de los pacientes con meningitis neumocócica, que tienen estudio neuropatológico, muestran arteritis o flebitis de los vasos cerebrales ${ }^{4}$. Estas arteriopatías pueden 
expresarse como infartos imagenológicos en 6\% de los pacientes, quienes concomitantemente pueden desarrollar hemorragias o trombosis venosas $^{3,4}$. También es muy frecuente la inflamación parenquimatosa difusa, como la cerebritis y más eventuales, las reacciones de estructuras ependimarias o ventriculares ${ }^{4}$. Esta amplia actividad inflamatoria que produce el neumococo dentro del SNC corresponde a respuestas ampliadas del sistema inmune en las infecciones neumocócicas, condición que podría generar una reactividad inmunológica tardía, capaz de inducir el desarrollo de vasculitis crónicas en las etapas postagudas de la infección ${ }^{5-7}$. Reactividad que ha sido interpretada como la perpetuación de una cascada inflamatoria independiente, causada por la desregulación en la especificidad inmunológica en ciertos pacientes ${ }^{6,8}$. La misma línea inmunológica ostentaría la meningitis crónica postinfección. Otra complicación infrecuente es el aumento del volumen ventricular que se observa en $2 \%$ de los pacientes ${ }^{2}$.

Se describe una paciente que desarrolló una meningitis neumocócica, complicada con vasculitis de vasos cerebrales y que evolucionó hacia una meningitis crónica, controlada con el uso de corticoides. Este trabajo fue aprobado por el Comité de Ética Científico del Servicio de Salud Metropolitano Oriente.

\section{Paciente}

Mujer de 53 años portadora de colitis ulcerosa inactiva, hipertensión arterial, diabetes mellitus y dislipidemia. En diciembre del año 2016 ingresó al Hospital del Salvador por una meningitis neumocócica confirmada por hemocultivos y cultivo del líquido cefalorraquídeo (LCR), que presentaba 28 células, con $64 \%$ polimorfonucleares (PMN), $6,1 \mathrm{~g} / \mathrm{L}$ proteínas y $0,2 \mathrm{mg} / \mathrm{dl}$ de glucosa. Se inició tratamiento con ceftriaxona, ampicilina y dexametasona, esta última suspendida después de cuatro días, según esquema habitual. La paciente después de una mejoría inicial se comprometió de conciencia, se mantuvo febril, con debilidad e hipoestesia de la extremidad superior derecha. Se realizó control de LCR que mostró incremento de la celularidad a $1.280 \times \mathrm{mm}^{3}$ con $98 \%$ de PMN. Se aumentó la cobertura antibiótica con meropenem, pero sin respuesta. Se realizó una resonancia magnética (RNM) de cerebro y angio-resonancia cerebral, que puso en evidencia un reforzamiento difuso de las leptomeninges, una lesión isquémica aguda pontina derecha, hemorragia subaracnoidea localizada en la convexidad y disminución del calibre arterial de todas las arterias cerebrales (Figura 1). La paciente empeoró cayendo en sopor profundo, un nuevo estudio de LCR mostró 3.170

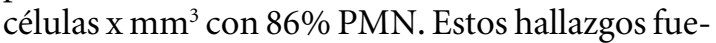
ron interpretados como vasculitis y se inició tratamiento con prednisona $60 \mathrm{mg}$ diarios, lográndose en pocos días la desaparición del síndrome febril, una mejoría clínica y caída en de la celularidad en el LCR a 36 células $x \mathrm{~mm}^{3}$ con $60 \%$ PMN, con 2,18 $\mathrm{g} / \mathrm{L}$ de proteínas. Un nuevo estudio con RNM, a los 28 días, mostró disminución del reforzamiento leptomeníngeo, persistencia en la disminución del calibre de los vasos sanguíneos de manera difusa, sin signos de hipertensión endocraneana (Figura 2). Los exámenes generales de laboratorio resultaron normales, VDRL y VIH no reactivos, niveles de complemento $\mathrm{C} 3$ y $\mathrm{C} 4$ y de inmunoglobulinas IgA, IgG e IgM normales, así como anticuerpos antinucleares y antineutrófilos negativos. Fue dada de alta con prednisona $60 \mathrm{mg} /$ día, con un esquema de disminución hasta su suspensión en tres meses. Un mes después de suspender los corticoides, consultó por inestabilidad de la marcha, sin otras molestias, por lo que se realizó una tomografía computada (TC) de cerebro, que mostró dilatación del sistema ventricular, con borramiento de los surcos de la convexidad. Fue rehospitalizada a los de 6 meses de su alta y un nuevo estudio del LCR mostró 50 células $\mathrm{x} \mathrm{mm}$, $46 \%$ de mononucleares y $1,45 \mathrm{~g} / \mathrm{L}$ de proteínas $\mathrm{y}$, además, incluyó PCR para micobacterias y toxoplasma, VDRL, cultivo para criptococo, bacteriano y hongos, todos lo cuales fueron negativos. La serología para toxoplasma fue negativa y un nuevo estudio de C3 y C4, inmunoglobulinas IgA, IgG e $\mathrm{IgM}$, anticuerpos antinucleares y antineutrófilos fue nuevamente negativo. La cuantificación de inmunoglobulinas con el método de inmunoturbidimetría fue normal, en particular IgG 4 que fue 4,2 mg/dL (rango: 3,9-86,4). Además, se realizó TC tórax-abdomen-pelvis que no mostró alteraciones patológicas. Sin embargo, una RNM de control mostró un aumento ventricular compatible con una hidrocefalia comunicante y un tap test positivo, siendo candidata para válvula ventrículo-peritoneal una vez normalizado el LCR. Se reinició tratamiento corticoidal, lográndose una buena respuesta, tanto en lo clínico como en el LCR, que

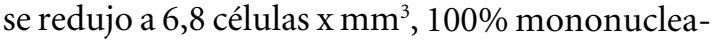




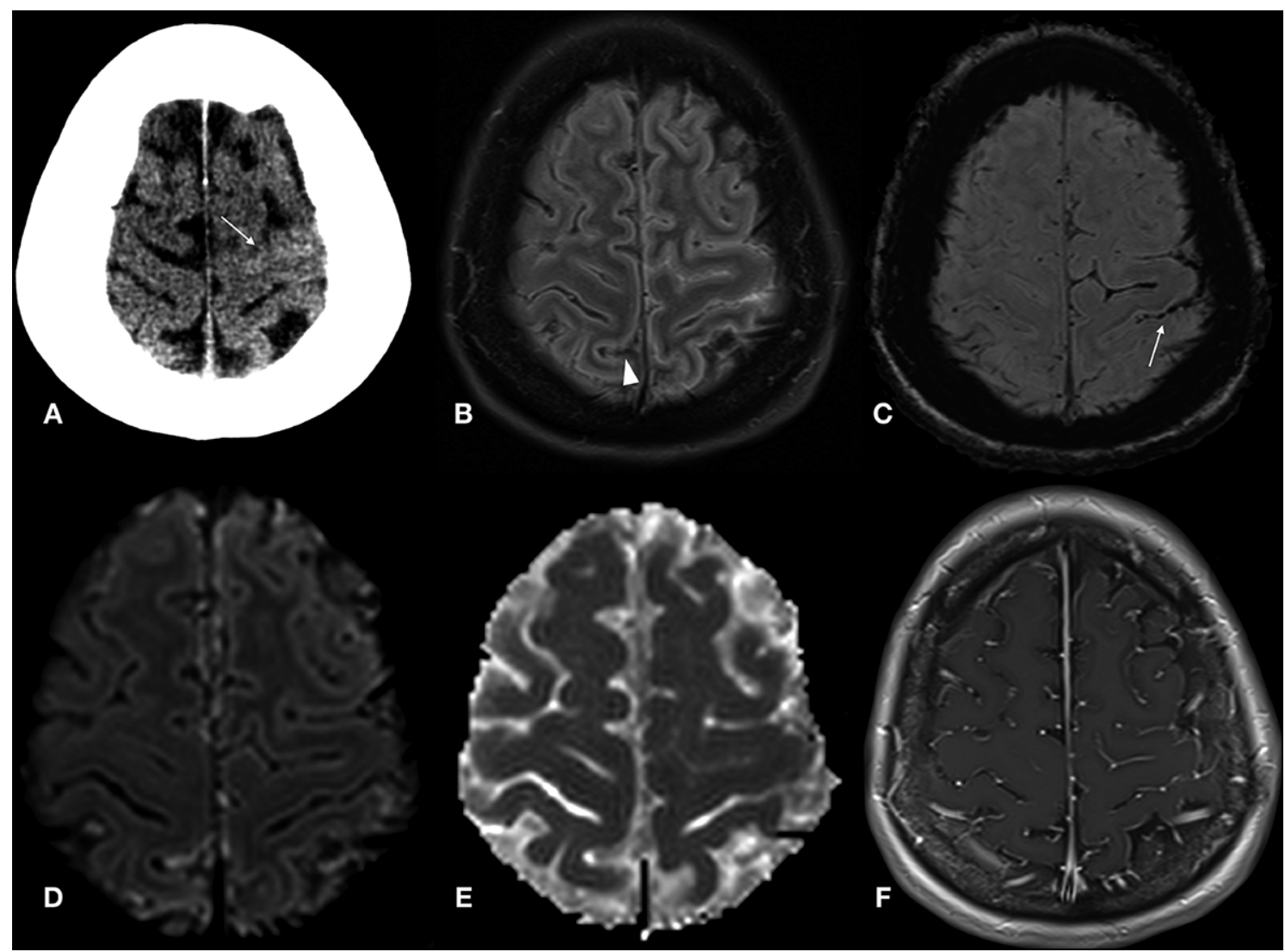

Figura 1. Imágenes al inicio del cuadro clínico: (A) Corte axial en tomografía computada muestra ocupación por contenido hiperdenso del surco precentral correspondiente a hemorragia subaracnoidea. (B) a (F) Cortes axiales en RM. (B) T2-FLAIR muestra contenido iso a hipertenso en la convexidad (punta de flecha en B), con ocupación de los surcos por contenido hiperintenso, con artefacto de susceptibilidad en SWI (Flecha en C), hallazgos correspondientes a HSA en resonancia y compromiso inflamatorio infeccioso. (D) y (E) DWI y ADC presenta ocupación del espacio subaracnoídeo con focos de restricción de la difusión, que reafirma la sangre en la convexidad. (F) T1 - Gadolinio con impregnación leptomeningea difusa, que apoya el diagnóstico de meningitis.

res y $1,3 \mathrm{~g} / \mathrm{L}$ de proteínas. Ante la negatividad del estudio infeccioso e inmunológico específico, el cuadro fue interpretado como el de una probable meningitis autoinmune, interpretación surgida de la hipercelularidad mantenida en el LCR y la mejoría con el uso de corticoides.

\section{Discusión}

Se ha presentado una paciente que después de una meningitis neumocócica desarrolló una meningitis crónica, que responde a corticoides como ha sido reportado por otros autores ${ }^{7}$. Se sabe que las meningitis debidas a neumococo pueden generar respuestas inmunitarias extendidas dentro del SNC, esta reactividad sería independiente de la precocidad y eficiencia del tratamiento antibiótico $^{6}$. En ese contexto se ha descrito en varios pacientes una agravación o reactivación de su meningitis con la suspensión programada de los esteroides al cuarto día y que solo la reposición del tratamiento corticoidal lograba mejorar ${ }^{7}$. Este fenómeno fue interpretado como un rebote inflamatorio, consecuencia de la brusca suspensión de los esteroides y que, supuestamente, una lenta disminución de su uso permitiría evitarlo ${ }^{9,10}$. Nuestra paciente parecía confirmar esa hipótesis debido a la agravación que experimentó en esa etapa, situación que se asoció a un aumento de 


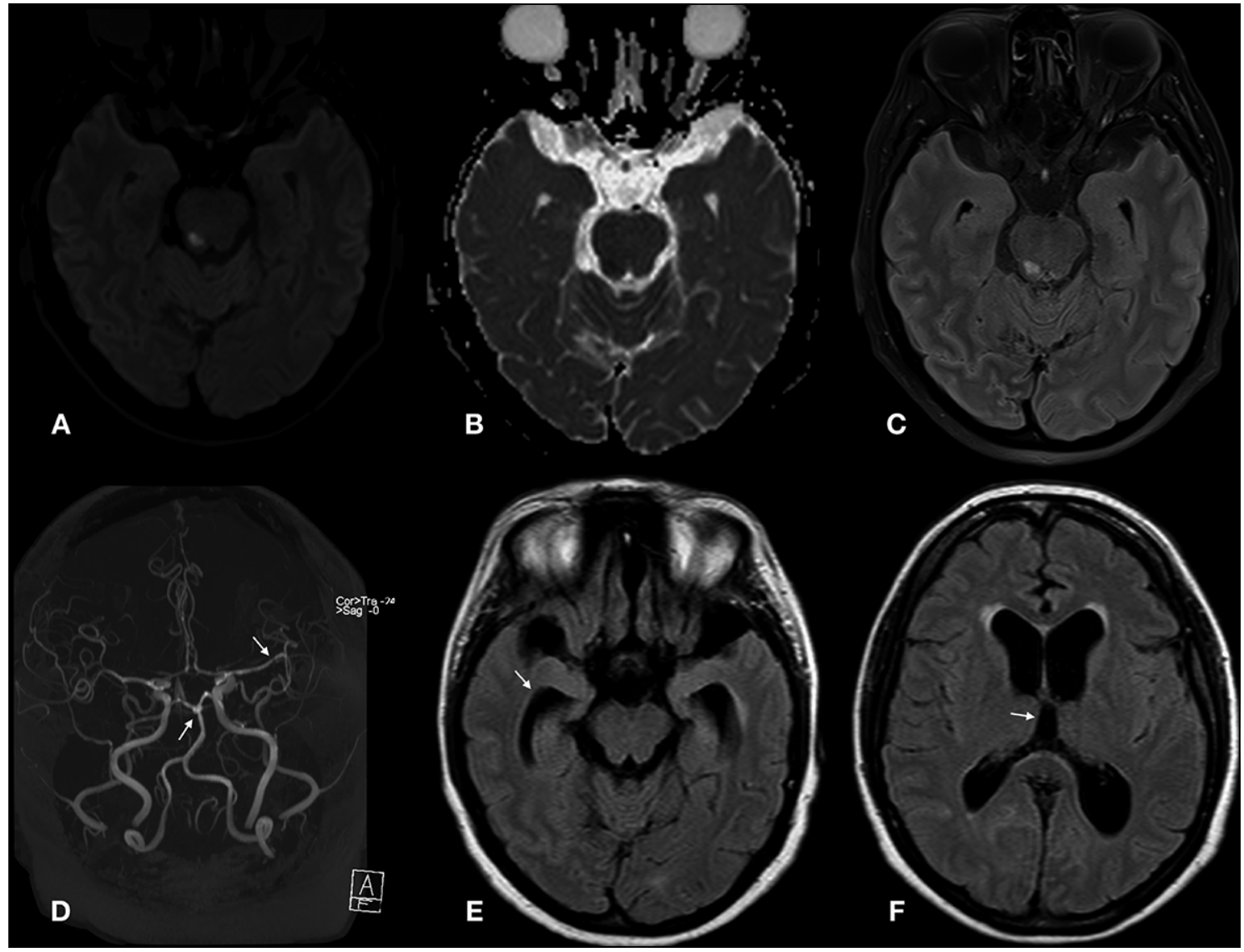

Figura 2. Imágenes obtenidas al momento de las complicaciones: (A), (B) y (C) Cortes axiales en DWI, ADC y FLAIR, respectivamente, muestran lesión isquémica aguda con restricción de la difusión, que refleja un de infarto agudo. (A) y (B) En el tegmento pontino derecho y (C) representación en T2-FLAIR. (D) Angiorresonancia TOF muestra disminución e irregularidad del calibre de los vasos intracraneanos (flechas), hallazgos compatibles con fenómeno vasculítico. (E) y (F) Cortes axiales en T2-FLAIR de control en segunda hospitalización, que muestra incremento de tamaño del sistema ventricular, compatible con hidrocefalia (flechas)

células en el LCR, en ausencia de bacterias. La reinstalación del tratamiento con prednisona 60 $\mathrm{mg}$ /día logró una mejoría clínica, pero a pesar de su suspensión gradual, no se impidió la reaparición de una actividad inflamatoria de las meninges al cuarto mes, con una pleocitosis del LCR que sugería una meningitis crónica.

En cada etapa de la evolución fueron descartadas tanto la reactivación como la recurrencia, debido a la ausencia de gérmenes, la no respuesta a los antibióticos, así como la excelente respuesta a los corticoides. Finalmente, el cuadro meníngeo adquirió el curso de una meningitis crónica. En este caso se pueden identificar tres causas principales para su génesis, la infecciosa directa, la neoplásica y la inmunológica inespecífica. Tanto la hipótesis de un origen infeccioso, como neoplásico fueron descartados convenientemente. La presencia de una meningitis crónica sin etiología identificable, salvo el antecedente de la infección neumocócica, permitiría definirla como una forma de meningitis autoinmune que mejora con el uso de corticoides que ha sido reconocida previamente ${ }^{6}$.

Está descrito que la meningitis neumocócica puede engrosar las meninges y originar por excepción una hidrocefalia ${ }^{4,6}$. Sin embargo, el engrosamiento meníngeo asociado a hidrocéfalo en la RNM cerebral y un fondo de ojo normal en esta paciente, nos planteó el diagnóstico diferencial con 
una enfermedad asociada a la sobreexpresión de IgG4. No obstante, la normalidad en los niveles de IgG4, ausencia de plasmocitos en el LCR, sin otras patologías sistémicas como fibrosis de glándulas salivares, de páncreas, de vías biliares o hígado y la ausencia de fibrosis en tejidos paraorbitario, que se vinculan habitualmente al desarrollo de esta discrasia, hace esta posibilidad improbable ${ }^{10}$. Por otra parte, la paciente no dio señales de compromiso vascular después de la etapa aguda, manteniendo sólo la reactividad meníngea postinfección por neumococo.

Por ello, creemos se trata de una meningitis crónica generada por algún mecanismo autoinmune, gatillado por la infección neumocócica. Existen algunas publicaciones en la literatura mundial que describen un cuadro similar al de nuestra paciente y donde se destaca la sensibilidad al tratamiento con corticoides ${ }^{7}$. No sabemos si el antecedente de colitis ulcerosa es un terreno inmunológico propicio para el desarrollo de este tipo de complicaciones pero, en los escaso reportes de asociación entre meninges y colitis ulcerosa, se trata de cuadros graves de paquimeningitis que no responden a tratamiento médico ${ }^{11}$ y que contrasta con la excelente respuesta a los corticoides de nuestra paciente.

Dado lo excepcional de las complicaciones descritas en esta meningitis neumocócica pensamos debemos estar alerta, especialmente porque la recurrencia de la meningitis con la suspensión de los esteroides no es una reactivación y podría ser la respuesta premonitoria de una nueva condición inmunitaria que permitiría el desarrollo de inflamaciones crónicas en estos pacientes ${ }^{12}$.

\section{Referencias}

1. Thigpen MC, Whitney CG, Messonnier NE, Zell ER, Lynfield R, Hadler JL, et al. Bacterial Meningitis in the United States, 1998-2007. N Engl J Med 2011; 364 (21): 2016-25.
2. van de Beek D, de Gans J, Spanjaard L, Weisfelt M, Reitsma JB, Vermeulen M. Clinical Features and Prognostic Factors in Adults with Bacterial Meningitis. N Engl J Med 2004; 351 (18): 1849-59.

3. Geno KA, Gilbert GL, Song JY, Skovsted IC, Klugman $\mathrm{KP}$, Jones C, et al. Pneumococcal Capsules and Their Types: Past, Present, and Future. Clin Microbiol Rev 2015; 28 (3): 871-99.

4. Engelen-Lee JY, Brouwer MC, Aronica E, van de Beek D. Pneumococcal meningitis: clinical-pathological correlations (MeninGene-Path). Acta Neuropathol Commun 2016; 4: 26.

5. Lucas A, Maung KK, Ratts R. Streptococcus pneumoniae intracranial abscess and post-infectious vasculitis. Infect Dis Rep 2017; 8 (4): 2-3.

6. Ribeiro S, Domingues V, Faria RM, Mendonça T. Invasive pneumococcal disease complicated by cerebral vasculitis, transient diabetes insipidus and spondylodiscitis. BMJ Case Rep 2013; 2-5.

7. Jorens PG, Parizel PM, Demey HE, Smets K, Jadoul $\mathrm{K}$, Verbeek MM, et al. Meningoencephalitis caused by Streptococcus pneumoniae: A diagnostic and therapeutic challenge. Diagnosis with diffusion-weighted MRI leading to treatment with corticosteroids. Neuroradiology 2005; 47 (10): 758-64.

8. Pugin D, Copin J-C, Goodyear M-C, Landis T, Gasche Y. Persisting Vasculitis After Pneumococcal Meningitis. Neurocrit Care 2006; 4 (3): 237-40.

9. Rojo-Enríquez A, Skromne-Eisenberg E, Irigoyen-Maldonado MC, Videgaray-Ortega F. Complicaciones neurológicas posteriores a la suspensión del esteroide en dos pacientes con meningitis por neumococo. Acta Medica Grupo Angeles 2010; 8 (1): 33-6.

10. Kamisawa T, Zen Y, Pillai S, Stone JH. IgG4-related disease. Lancet 2015; 385 (9976): 1460-71.

11. Xia Z, Chen-Plotkin A, Schmahmann JD. Hypertrophic pachymeningitis and cerebral venous sinus thrombosis in inflammatory bowel disease. J Clin Neurosci 2010; 17 (11): 1454-6.

12. Morimoto S, Takao M, Sakurai K, Sunagawa M, Komiya $\mathrm{T}$, Arai T, et al. Steroid responsive chronic meningoencephalitis reminiscent of rheumatoid meningitis: a case report. Rinsho Shinkeigaku 2015; 55 (8): 573-9. 